\title{
Performance of the Modified Dolphin Monitoring Operator for Weight Optimization of Skeletal Structures
}

\author{
Ali Kaveh ${ }^{1 *}$, Seyed Rohollah Hosseini Vaez ${ }^{2}$, Pedram Hosseini \\ ${ }^{1}$ Centre of Excellence for Fundamental Studies in Structural Engineering, \\ School of Civil Engineering, Iran University of Science and Technology, \\ Narmak, Tehran-16, Iran \\ 2 Department of Civil Engineering, Faculty of Engineering, \\ University of Qom, Qom, \\ * Corresponding author, e-mail: alikaveh@iust.ac.ir
}

Received: 17 May 2018, Accepted: 28 August 2018, Published online: 01 October 2018

\begin{abstract}
In this study, the Modified Dolphin Monitoring (MDM) operator is used to enhance the performance of some metaheuristic algorithms. The MDM is a recently presented operator that controls the population dispersion in each iteration. Algorithms are selected from some well established algorithms. Here, this operator is applied on Differential Evolution (DE), Particle Swarm Optimization (PSO), Genetic Algorithm (GA), Vibrating Particles System (VPS), Enhanced Vibrating Particles System (EVPS), Colliding Bodied Optimization (CBO) and Harmony Search (HS) and the performance of these algorithms are evaluated with and without this operator on three wellknown structural optimization problems. The results show the performance of this operator on these algorithms for the best, the worst, average and average weight of the first quarter of answers.
\end{abstract}

Keywords

Modified Dolphin Monitoring (MDM) operator, weight optimization, frame structures, truss structures, frequency constraints, metaheuristic algorithms

\section{Introduction}

Optimization methods are categorized into two general groups consisting of mathematical programming methods and metaheuristic approaches. Nowadays metaheuristic algorithms have been widely used for solving optimization problems because these have not some of the defect corresponding to the first group of methods and are easy to use and require affordable computational time [1]. Many metaheuristic algorithms are introduced in the last two decades, some of these are as follows:

Genetic Algorithm (GA) [2], Differential Evolution (DE) [3], Particle Swarm Optimization (PSO) [4], Bat algorithm [5], Dolphin Echolocation Optimization (DEO) [6], Simplified Dolphin Echolocation (SDE) algorithm [7, 8], Grey wolf optimizer [9], Vibrating Particles system and its enhanced version (VPS and EVPS) [10, 11], MODRO algorithm [12], Colliding bodies Optimization (CBO) [13], Harmony Search (HS) [14], Krill Herd (KH) algorithm [15], Electro search algorithm [16], Moving Morphable Components (MMCs) [17], Jaya algorithm [18], Slap
Swarm Algorithm (SSA) [19], Improved fruit fly optimization algorithm [20], Differential Big Bang-Big Crunch algorithm [21].

Metaheuristic algorithms have found many applications in different areas of applied mathematics, engineering, medicine, economics, and other sciences [22]. In optimization problems, there are always some requirements that should be minimized such as material, time, cost of the project and etc, and ultemately the final aim is gaining an economical result. As mentioned, many metaheuristic methods are introduced in last two decades, maybe it can be expressed that all of them have some opportunities in comparison with other methods for each problem. But there is a basic question and that is where each metaheuristic algorithm is suitable, especially, when a problem is evaluated for the first time and there is no previous optimal answer available. In this situation, it is possible that the selected algorithm to be entrapped in local optima. Also, it is possible that the obtained answer have a great 
difference with the optimum one. In the practical application of the metaheuristic methods, all of the answers near to the optimum answer are valuable but the answers with a great difference with the optimum answer are not valuable and it is not clear for the problems that are being solved for the first time. In other words, some algorithms are not suitable for several optimization problems and also, some algorithms should be tunned for a specific set of problems. The MDM operator has some feature for controlling the population dispersion in each variable and iteration. Addition of this operator to any algorithm prevents the algorithm to be trapped in local optima in comparison to the algorithm without this operator. Generally, this operator enhances the performance of the algorithms and the optimum designs of all algorithms with this operator are closer to each other corresponding to a suitable value.

It should be noted this operator does not cause any change in the main steps of the metaheuristic algorithms. Optimum design of structures is performed to gain a suitable design with more economical structural cost. In this study, Modified Dolphin Monitoring (MDM) operator is used to enhance the performance of seven metaheuristic algorithms when applied to three well-known structural optimization problems. These problems consist of the optimum weight design of a truss and a frame designed in according to AISC constraints [23] and one truss structure with frequency constraints. The results are presented for seven algorithms with and without the MDM operator. Benefits of using this operator are presented in the last part of section 2 .

This paper is organized as follow: In the first section introduction is presented. A brief explanation of seven algorithms and the MDM operator is provided in section 2 and the formulation of the objective function is introduced in section 3. Section 4 consists of three well-known structural optimization problems with a brief explanation of their constraints and finally the concluding remarks are presented in section 5 .

\section{A brief review of seven metaheuristic algorithms and the MDM operator}

\subsection{Differential Evolutionary}

As Differential Evolutionary (DE) method was presented by Storn and Price [3]. This method is based on calculating the difference between two randomly selected vectors. Initial vectors are created randomly in a permissible range. For the next steps, according to the difference of the vectors and crossover operator, all vector are updated.

\subsection{Particle Swarm Optimization}

Particle Swarm Optimization (PSO) algorithm was proposed by Kennedy and Eberhart [4]. This algorithm adopted from the behaviour of the animal flacking. In the first step, the algorithm creates a random population in permissible range. The velocity determines the next location of each population according to global best and the population best positions.

\subsection{Genetic Algorithm}

Genetic algorithm (GA) was introduced by Holland [2] that was inspired by biological evolution. The initial population is generated randomly in the permissible search space. This algorithm selects the better populations for next steps, and using a crossover and mutation operators tries to improve the populations.

\subsection{Vibrating Particles Systems}

Vibrating Particles Systems (VPS) algorithm was developed by Kaveh and Ilchi Ghazaan [24]. This method is adapted from the free vibration of single degree of freedom systems with viscous damping so that each answer is modelled as a particle that moves to its equilibrium position. New positions are updated according to a historically best position.

\subsection{Enhanced Vibrating Particles System}

Enhanced Vibrating Particles System (EVPS) is a modified version of the VPS algorithm that was presented by the authors [11]. This algorithm employs some new approach to gaining the optimum answer.

\subsection{Colliding Bodies Optimization}

Colliding Bodies Optimization (CBO) algorithm was introduced by Kaveh and Mahdavi [13]. This algorithm is based on a one-dimensional collision between two bodies with each agent being modeled as an object. Initial agents are generated randomly in a permissible range. Next steps is performed according to velocities and the masses of each agent.

\subsection{Harmony Search}

Harmony Search (HS) algorithm was proposed by Geem et al. [14]. This method is based on the promotion process of a musician. Initial vectors are generated using random numbers in a feasible space. This algorithm consists of some operators. Next vectors is updated using these operators. 


\subsection{Modified Dolphin Monitoring operator}

Dolphin monitoring (DM) was introduced by Kaveh and Farhoudi [25] for the first time. This algorithm was enhanced DM operator and presented Modified Dolphin monitoring (MDM) by Kaveh et al. [26]. It should be noted that this operator was used for layout optimization of planar braced frames [27]. These operators control the population dispersion for each variable and iteration. DM expresses that the mode value for all population for each variable should be repeated as a specified magnitude for each iteration. If the number of mode repetition is bigger or smaller than this specified this value some approaches are used to until these two values are equal [25]. MDM operator determines a range and expresses that all values for all population and each variable should be in this range in certain numbers [26]. The range is equal to average $\pm(15 \%)$ standard deviation for each variable and the certain number is calculated according to Eq. (1).

$$
M P_{i}=10+60\left[\frac{i-1}{\text { Maximum number of iterations }-1}\right] \text {, }
$$

where $M P_{i}$ is the number of values should be in the range in percent for the $i$ th iteration.

MDM operator applies to metaheuristic algorithms and enhances the performance of them to find the optimum design. In fact, this operator gives the ability to the algorithms to escape from the local optima. If the selected algorithm is not suitable for a specified problem or the parameters of the algorithm is not turned properly, this operator will help the algorithm to find an appropriate answer. The pseudocode of the MDM operator is as follow:

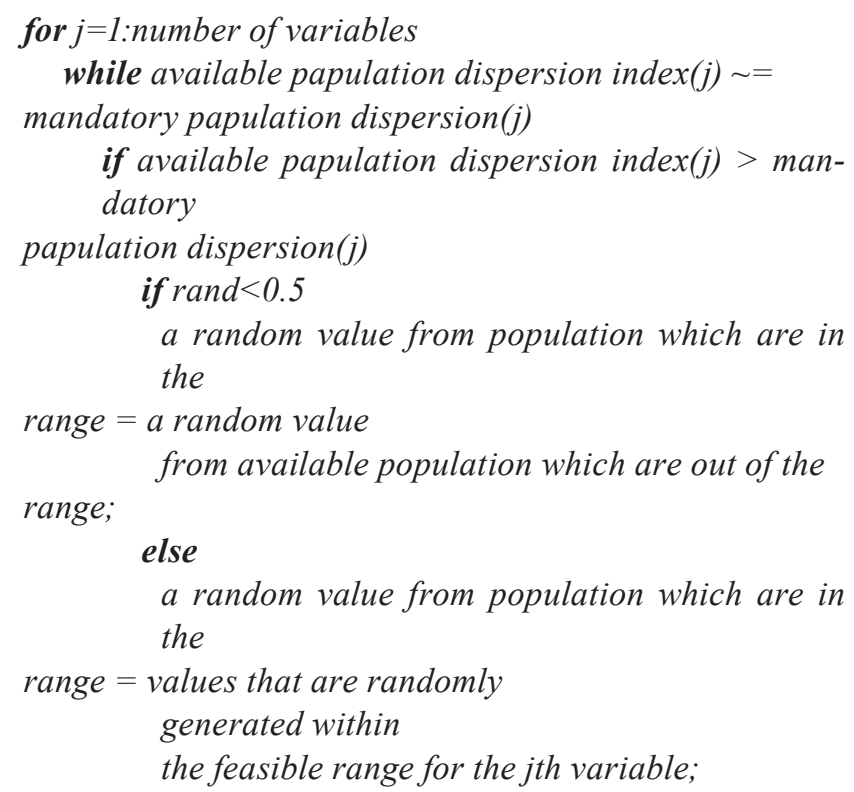

end

elseif available papulation dispersion index $(j)<$ mandatory papulation dispersion( $(j)$

\section{if rand $<0.5$}

a random value from population which are out of

the range $=$ the best available

optimal variable for the stage;

else

a random value from population which are out

of the range $=$ values that are in the desired range;

end

end

end

end

In above pseudocode, available population dispersion index is the percent of the population in the mentioned range for each variable and mandatory population dispersion is the number of values which should be in the range in percent for the ith iteration according to Eq. (1). It should be noted that, if the population within the defined range is not equal to the value specified in Eq. (1), the MDM operator replaces the new values in the answers with some mechanisms that are presented in the pseudocode of the MDM operator. These approaches improve the search ability power of the metaheuristic algorithms. Based on the explanations, this operator:

- Controls the population dispersion for each variable and iteration,

- Controls the speed of the convergence,

- Enhances the algorithm's ability to escape from local optima,

- Balancing between exploration and exploitation of the algorithms,

- Enhances the searchability of algorithms, and obtains a suitable answer as an optimal answer.

\section{Formulation of the optimization problems}

In this section, the goal is to minimize the weight of skeletal structures satisfying certain design requirements. Design requirements for the first two problems are the strength and displacements constraints according to LRFD-AISC specification [23], and the third one considers frequency constraints. The mathematical formulation of optimal design of the problems can be presented as follow:

$$
\begin{aligned}
& \text { Find }\{x\}=\left[x_{1}, x_{2}, \ldots, x_{n g}\right] \quad x_{i} \in S_{i} \\
& \text { To minimize } W(\{\mathrm{x}\})=\sum_{i=1}^{n m} \rho_{i} A_{i} L_{i}
\end{aligned}
$$


where $\{x\}$ is a set of design variables containing the crosssectional area of W-sections; $n g$ is the number of design variables; $W(\{x\})$ is the weight of the skeletal structure; $n m$ is the number of elements of the skeletal structure; $\rho_{i}$ presents the material density of the ith member; $A_{i}$ and $L_{i}$ present the cross-sectional area and the length of the ith member, respectively. It above equation, $x_{i}$ is the number of a W-section and $A_{i}$ is the cross-sectional area of the ith group.

In this study, two problems are considered as discrete optimization and one is for continues optimization problem. To control the requirements of each problem, penalty approach is used according to the following equation:

$$
\text { fitness }(x)=\left(1+\varepsilon_{1} \cdot v\right)^{\varepsilon_{2}} \times w\{(x)\}, v=\sum_{j=1}^{n c} \max \left(0, v_{i}\right) .
$$

fitness $(x)$ and $v$ are the fitness function and the sum of the violations for each problem. In this study, $\varepsilon_{1}$ and $\varepsilon_{2}$ are set to 0.3 and 1 , respectively, and $n c$ is the total number of requirements for each individual design. It should be noted that specified constraints for each problem are presented in subsequent section.

\section{Numerical problems}

In this section, three well-known skeletal structures are considered to investigate the performance of the MDM operator on seven algorithms. All results are presented with and without the incorporating this operator. As mentioned in section 3, minimizing the weight of three skeletal structures is conducted in this study, these problems are as follow:

- A 3-bay 24-story steel frame with AISC-LRFD [23] constraints.

- A 582-bar tower truss structure with AISC-LRFD [23] constraints.

- A 72-bar spatial truss structure with frequency constraints.

It should be noted that all problems have been solved 30 times independently, also, the number of population and number of iterations are taken as 60 and 1000, respectively.

\subsection{A 3-bay 24- story steel frame with AISC-LRFD constraints}

A 3-bay 24 story frame consisting of the schematic, applied loads and the numbering of the member groups is illustrated in Fig. 1. This structure consists of 100 joints and 168 elements that are collected in 20 groups (16 column groups and 4 beam groups). The beam and column element groups are selected from all $267 \mathrm{~W}$-shape and W-14 sections, respectively. The material has a modulus of elastic

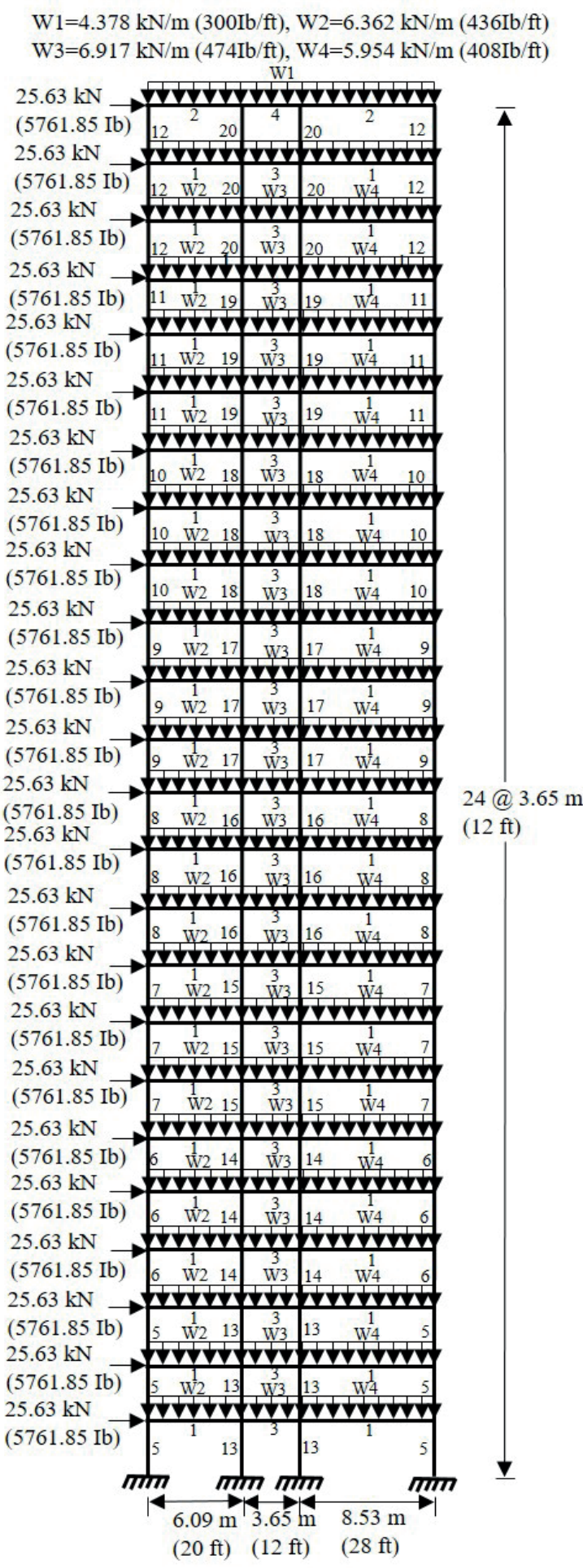

Fig. 1 Schematic of a 3-bay 24-story frame

ity equal to $E=205 \mathrm{GPa}(29,732 \mathrm{ksi})$ and a yield stress of $f_{y}=230.28 \mathrm{MPa}(33.4 \mathrm{ksi})$. The effective length factors of the members are computed as $k_{x} \geq 1.0$ for a sway permitted frame and the out-of-plane effective length factor is determined as $k_{y}=1.0$. All columns and beams are considered as non-braced along their lengths. According to AISC-LRFD [23] constraints are as follow: 
(a) Maximum lateral displacement

$\frac{\left|\Delta_{T}\right|}{H}-R_{k} \leq 0$

(b) The inter-story drift constraints

$\frac{\left|d_{i}\right|}{h_{i}}-R_{l} \leq 0 ; i=1,2, \ldots, n s$.

(c) Strength constraints

$$
\begin{gathered}
\frac{P_{u}}{2 \phi_{c} P_{n}}+\left[\frac{M_{u x}}{\phi_{b} M_{n x}}+\frac{M_{u y}}{\phi_{b} M_{n y}}\right]-1 \leq 0 ; \text { for } \frac{P_{u}}{\phi_{c} P_{n}}<0.2 \\
\frac{P_{u}}{\phi_{c} P_{n}}+\frac{8}{9}\left[\frac{M_{u x}}{\phi_{b} M_{n x}}+\frac{M_{u y}}{\phi_{b} M_{n y}}\right]-1 \leq 0 ; \text { for } \frac{P_{u}}{\phi_{c} P_{n}} \geq 0.2
\end{gathered}
$$

where $\Delta_{T}$ is the maximum lateral displacement of the roof; $H$ is the height of the frame structure; $R_{k}$ is the maximum drift index (in this study it is equal to); $d_{i}$ is the inter story drift; $h_{i}$ is the story height of the ith floor; $n s$ is the total number of stories; $R_{1}$ shows the inter story drift index and its limitation is like $R_{k}$ index; $P_{u}$ is the required strength (tension or compression); $P_{n}$ is the nominal axial strength [23](tension or compression); $\varnothing_{c}$ is the resistance factor $\left(\varnothing_{c}=0.9\right.$ for tension and $\varnothing_{c}=0.85$ for compression); $M_{u}$ (containing $M_{u x}$ and $M_{u y}$ ) is the required flexural strengths; $M_{n}$ (containing $M_{n x}$ and $M_{n y}$ ) is the nominal flexural strengths [23] (for two-dimensional frames $M_{u y}$ $=0$ and $M_{n y}=0$ ); and $\varnothing_{b}$ presents the flexural resistance reduction factor $\left(\varnothing_{b}=0.90\right)$.

Table 1 contains the results of seven algorithms consisting of DE, PSO, GA, VPS, EVPS, CBO and HS with the effect of the MDM operator and without this effect. In this table, the best, worst and mean weights for all and mean weight of the first quarter of answers for each method is presented.

It can be seen that the lightest design is found by EVPSMDM which is $893.95 \mathrm{kN}$. Although all optimum designs with the effect of MDM operator have reached suitable

\begin{tabular}{|c|c|c|c|c|c|c|c|}
\hline \multirow[t]{2}{*}{ Element group } & \multicolumn{7}{|c|}{ Optimal W-Shaped sections } \\
\hline & $\mathrm{DE}$ & PSO & GA & VPS & EVPS & $\mathrm{CBO}$ & HS \\
\hline 1 & W30x90 & W30x108 & W30x90 & W30x90 & W30x90 & W30x108 & W30x90 \\
\hline 2 & W8x18 & W10x112 & W6x 15 & W14x68 & W6x 15 & W8x18 & W8x 18 \\
\hline 3 & W24x62 & W18x143 & W27x84 & W27x84 & W24x55 & W24x55 & W24x62 \\
\hline 4 & W6x8.5 & W5x16 & W6x8.5 & W10x39 & W6x9 & W6x8.5 & W6x9 \\
\hline 5 & W14x145 & $\mathrm{W} 14 \times 233$ & W14x132 & W14x159 & W14x159 & W14x132 & W14x159 \\
\hline 6 & W14x109 & $\mathrm{W} 14 \times 120$ & W14x109 & W14x82 & W14x132 & $\mathrm{W} 14 \times 120$ & W14x176 \\
\hline 7 & $\mathrm{~W} 14 \times 120$ & $\mathrm{~W} 14 \times 132$ & W14x82 & W14x90 & W14x109 & W14x90 & W14x99 \\
\hline 8 & $\mathrm{~W} 14 \times 90$ & $\mathrm{~W} 14 \times 90$ & W14x90 & W14x53 & W14x74 & W14x90 & W14x82 \\
\hline 9 & W14x61 & W14x109 & W14x90 & W14x61 & W14x61 & W14x61 & W14x61 \\
\hline 10 & W14x38 & $\mathrm{W} 14 \times 120$ & W14x53 & W14x90 & W14x38 & W14x48 & W14x48 \\
\hline 11 & W14x38 & W14x90 & W14x34 & W14x34 & W14x30 & W14x38 & W14x30 \\
\hline 12 & W14x26 & W14x53 & W14x22 & W14x61 & W14x22 & W14x22 & W14x22 \\
\hline 13 & W14x90 & W14x82 & W14x90 & W14x90 & W14x90 & W14x90 & W14x90 \\
\hline 14 & W14x109 & W14x74 & W14x99 & W14x145 & W14x99 & W14x90 & W14x82 \\
\hline 15 & W14x90 & W14x145 & W14x109 & W14x132 & W14x90 & W14x90 & W14x90 \\
\hline 16 & W14x82 & W14x233 & W14x82 & W14x193 & W14x90 & W14x74 & W14x82 \\
\hline 17 & W14x74 & W14x132 & W14x61 & W14x90 & W14x74 & W14x74 & W14x68 \\
\hline 18 & W14x61 & W14x145 & W14x53 & W14x99 & W14x61 & W14x53 & W14x53 \\
\hline 19 & W14x30 & $\mathrm{W} 14 \times 22$ & W14x34 & $\mathrm{W} 14 \times 48$ & W14x38 & $\mathrm{W} 14 \times 30$ & W14x34 \\
\hline 20 & W14x22 & W14x193 & W14x22 & W14x22 & W14x22 & W14x22 & W14x22 \\
\hline Best weight (kN) & 901.64 & 1362.655 & 920.525 & 1025.656 & 894.03 & 962.55 & 905.48 \\
\hline Worst weight (kN) & 994.0635 & 2891.41 & 1020.923 & 1149.656 & 953.6786 & 1026.734 & 987.8225 \\
\hline Mean weight (kN) & 915.8925 & 1879.07 & 945.6831 & 1081.354 & 904.0907 & 978.5107 & 925.4 \\
\hline $\begin{array}{l}\text { Mean weight of the first quar- } \\
\text { ter of the best answers }(\mathrm{kN})\end{array}$ & 900.3324 & 1468.32 & 918.7998 & 1037.241 & 896.0129 & 952.9905 & 899.0706 \\
\hline
\end{tabular}

Table 1 Results of seven algorithms with and without the effect of the MDM operator for the 3-bay 24-story frame 


\begin{tabular}{|c|c|c|c|c|c|c|c|}
\hline \multirow[t]{2}{*}{ Element group } & \multicolumn{7}{|c|}{ Optimal W-shaped section using MDM operator } \\
\hline & $\mathrm{DE}$ & PSO & GA & VPS & EVPS & $\mathrm{CBO}$ & HS \\
\hline 1 & W30x90 & W30x90 & W30x90 & W30x90 & W30x90 & W30x90 & W30x90 \\
\hline 2 & W10x22 & W6x15 & W5x19 & W6x15 & W6x15 & W6x15 & W6x15 \\
\hline 3 & W24x55 & W24x55 & W24x55 & W21x44 & W24x55 & W24x55 & W24x55 \\
\hline 4 & W6x 16 & W6x8.5 & W6x8.5 & W6x8.5 & W6x8.5 & W6x8.5 & W8x10 \\
\hline 5 & W14x159 & W14x159 & W14x159 & W14x145 & W14x159 & W14x132 & W14x 159 \\
\hline 6 & W14x132 & W14x132 & W14x109 & W14x159 & W14x132 & W14x109 & W14x132 \\
\hline 7 & W14x109 & W14x109 & W14x120 & W14x99 & W14x109 & W14x90 & W14x99 \\
\hline 8 & W14x74 & W14x74 & W14x90 & W14x74 & W14x74 & W14x90 & W14x90 \\
\hline 9 & W14x68 & W14x53 & W14x61 & W14x68 & W14x61 & W14x61 & W14x68 \\
\hline 10 & W14x38 & W14x43 & W14x38 & W14x61 & W14x38 & W14x74 & W14x43 \\
\hline 11 & W14x34 & W14x34 & W14x38 & W14x30 & W14x34 & W14x30 & $\mathrm{W} 14 \times 30$ \\
\hline 12 & W14x22 & W14x22 & $\mathrm{W} 14 \times 22$ & W14x22 & $\mathrm{W} 14 \times 22$ & W14x22 & $\mathrm{W} 14 \times 22$ \\
\hline 13 & W14x90 & W14x90 & W14x90 & W14x109 & W14x90 & W14x99 & W14x90 \\
\hline 14 & W14x99 & W14x99 & W14x109 & W14x99 & W14x99 & W14x109 & W14x99 \\
\hline 15 & W14x90 & W14x90 & W14x90 & W14x109 & W14x90 & W14x109 & W14x99 \\
\hline 16 & W14x90 & W14x90 & W14x82 & W14x99 & W14x90 & W14x90 & W14x82 \\
\hline 17 & W14x68 & W14x82 & W14x74 & W14x74 & W14x74 & W14x82 & W14x68 \\
\hline 18 & W14x61 & W14x61 & W14x61 & W14x48 & W14x61 & W14x43 & W14x61 \\
\hline 19 & W14x34 & W14x34 & W14x30 & W14x38 & W14x34 & W14x38 & W14x34 \\
\hline 20 & W14x22 & W14x22 & $\mathrm{W} 14 \times 22$ & $\mathrm{~W} 14 \times 22$ & W14x22 & W14x22 & $\mathrm{W} 14 \times 22$ \\
\hline Best weight (kN) & 896.1678 & 895.3705 & 896.55 & 901.58 & 893.9539 & 897.29 & 896.7 \\
\hline Worst weight (kN) & 904.5019 & 959.6632 & 989.14 & 1002.944 & 896.5583 & 980.59 & 950.42 \\
\hline Mean weight (kN) & 898.19 & 918.9328 & 922.18 & 937.41 & 894.9684 & 928.4 & 918.7902 \\
\hline $\begin{array}{l}\text { Mean weight of the first quar- } \\
\text { ter of the best answers (kN) }\end{array}$ & 895.63 & 896.0737 & 915.4977 & 922.44 & 893.9616 & 899.2201 & 898.47 \\
\hline
\end{tabular}

values. Fig. 2 illustrates the convergence curves of the seven algorithms with and without the effect of the MDM operator for the best optimal design and average answer of all runs for this problem.

\subsection{A 582-bar tower truss structure with AISC-LRFD constraints}

The schematic of the 582-bar tower truss with the height of $80 \mathrm{~m}$ is presented in Fig. 3. The symmetry of the tower around $\mathrm{x}$-axis and $\mathrm{y}$-axis is considered to group the 582 members into 32 independent size variables. A single load case is considered consisting of the lateral loads of $5.0 \mathrm{kN}$ applied in both $\mathrm{x}$ and $\mathrm{y}$ directions and a vertical load of -30 $\mathrm{kN}$ applied in the $\mathrm{z}$-direction in all nodes of the tower. A discrete set of 137 economical standard steel sections selected from $\mathrm{W}$-shape profile list based on area and radii of gyration properties is used to size the variables. The lower and upper bounds on size variables are taken as $39.74 \mathrm{~cm}^{2}$ and 1387.09 $\mathrm{cm}^{2}$, respectively. The stress limitations of the members are imposed according to the provisions of AISC-LRFD
[23]. The other constraint is the limitation of nodal displacements (these should not be more than $8.0 \mathrm{~cm}$ or $3.15 \mathrm{in}$. in any direction). Also, the maximum slenderness ratio is limited to 300 for tension members, and it is recommended to be 200 for compression members according to AISC-LRFD design code provisions [23].

Optimal, the mean and the mean weight of the first quarter of the best answers are provided in Table 2 .

Table 2 shows that the best designs are achieved with EVPS, EVPS-MDM and DE-MDM which are $21.032 \mathrm{~m}^{3}$. Fig. 4 illustrates the convergence histories using the mentioned algorithms with the effect of the MDM operator and without this effect for best optimal design and mean answer.

\subsection{A 72-bar spatial truss structure with frequency constraints}

The third problem is a 72-bar spatial truss that as illustrated in Fig. 5. This truss structure has 20 nodes and 48 degrees of freedom, and four non-structural masses of $2270.0 \mathrm{~kg}$ are attached to the nodes $1-4$. All elements of the structure 

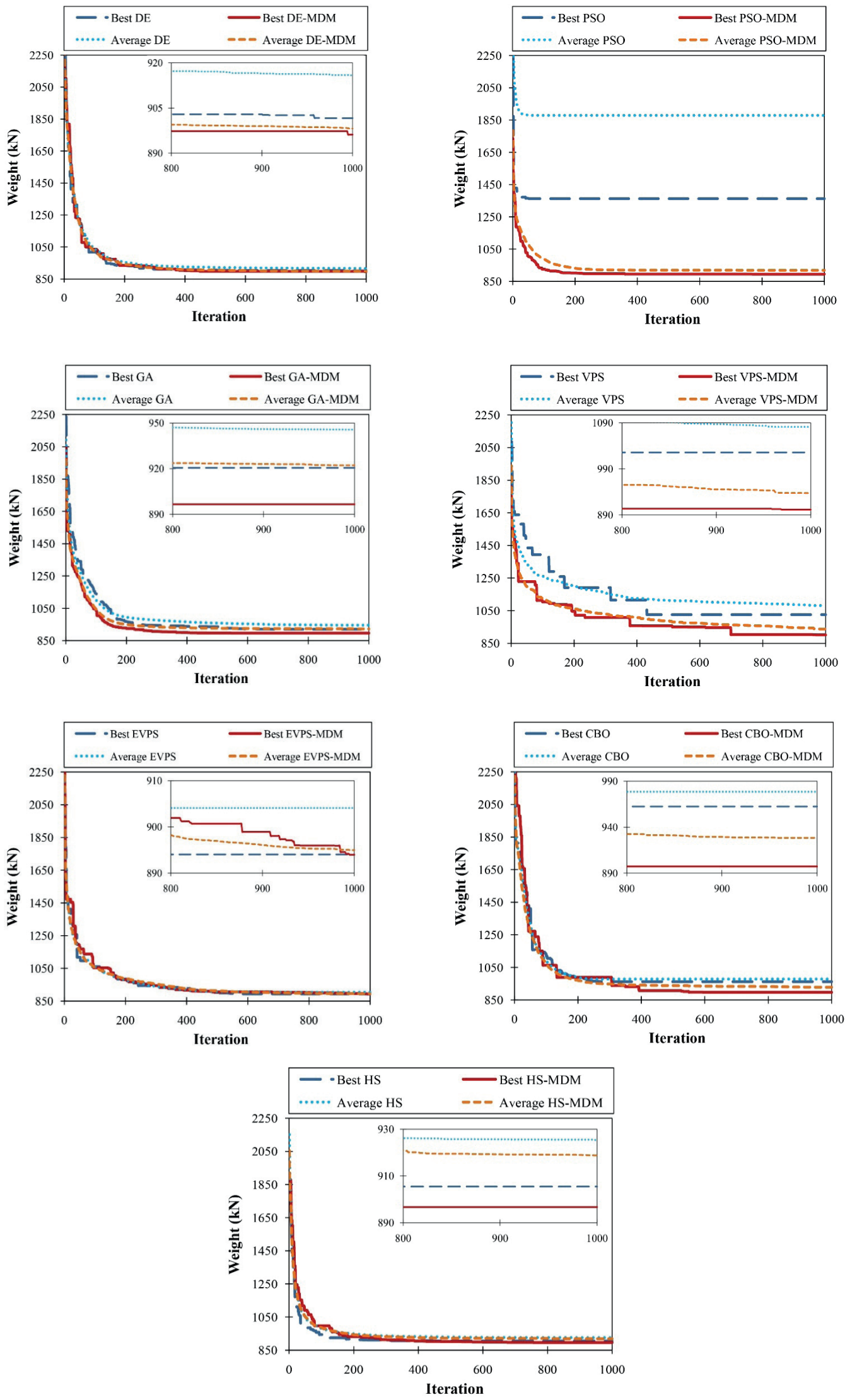

Fig. 2 Convergence curves of the seven algorithms with the effect of the MDM operator and without this effect for best optimal design and average answers for the 3-bay 24-story frame. 


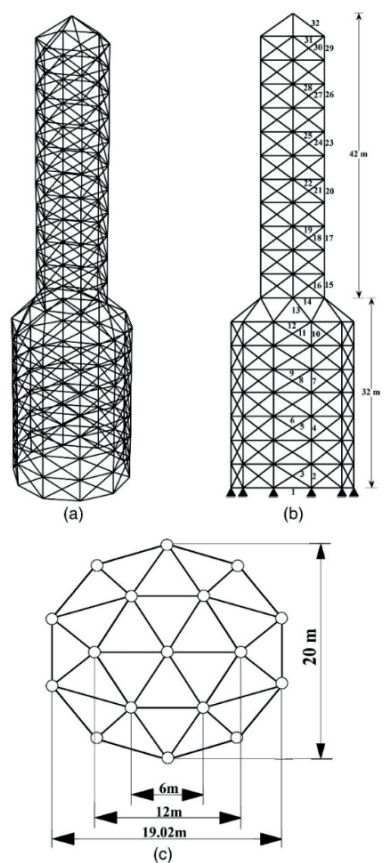

Fig. 3 Schematic of the 582-bar tower truss have a modulus of elasticity $E=6.89 \times 1010 \mathrm{~N} / \mathrm{m}^{2}$, density $\rho=2770 \mathrm{~kg} / \mathrm{m}^{3}$, and cross-sectional area $\mathrm{A}=0.0025 \mathrm{~m}^{2}$. In this problem, the layout of the truss is considered unchanged during the optimization and only the size optimization of this truss structure is investigated according to frequency constraints $\left(\omega_{1}=4 \mathrm{~Hz}\right.$ and $\left.\omega_{3} 6 \mathrm{~Hz}\right)$. Also, the minimum cross-sectional of all design variables is considered as $0.64510-4 \mathrm{~m}^{2}$.

Table 3 reports a comparison of the optimal results gained by the utilized algorithms for the effect of this operator and without this effect. It can be seen that the optimal weight is obtained by EVPS algorithm with the effect of the proposed operator.

Fig. 6 shows the penalized weight convergence history curves obtained by the seven used algorithms with the effect of the MDM operator and without this effect for best optimal design and average answer of all runs of this problem.

Table 2 Results of seven algorithms with and without the effect of the MDM operator for the 582-bar tower truss

\begin{tabular}{|c|c|c|c|c|c|c|c|}
\hline \multirow[t]{2}{*}{ Element group } & \multicolumn{7}{|c|}{ Optimal sections } \\
\hline & $\mathrm{DE}$ & PSO & GA & VPS & EVPS & $\mathrm{CBO}$ & HS \\
\hline 1 & 39.74186 & 39.74186 & 39.74186 & 39.74186 & 39.74186 & 39.74186 & 41.87088 \\
\hline 2 & 159.3545 & 159.3545 & 143.8707 & 169.0319 & 159.3545 & 136.1288 & 123.2256 \\
\hline 3 & 45.67733 & 45.67733 & 53.2257 & 45.67733 & 45.67733 & 53.2257 & 58.90311 \\
\hline 4 & 109.6772 & 109.6772 & 115.4836 & 128.3868 & 109.6772 & 114.1933 & 114.1933 \\
\hline 5 & 45.67733 & 45.67733 & 45.67733 & 47.35474 & 45.67733 & 45.67733 & 47.35474 \\
\hline 6 & 39.74186 & 41.87088 & 39.74186 & 45.67733 & 39.74186 & 39.74186 & 41.87088 \\
\hline 7 & 90.96756 & 90.96756 & 94.19336 & 75.48372 & 85.80628 & 90.96756 & 100.645 \\
\hline 8 & 45.67733 & 45.67733 & 45.67733 & 49.35474 & 45.67733 & 45.67733 & 45.67733 \\
\hline 9 & 39.74186 & 41.87088 & 39.74186 & 47.35474 & 39.74186 & 39.74186 & 39.74186 \\
\hline 10 & 81.29016 & 85.80628 & 90.96756 & 84.51596 & 85.80628 & 84.51596 & 66.45148 \\
\hline 11 & 45.67733 & 45.67733 & 45.67733 & 47.35474 & 45.67733 & 45.67733 & 49.35474 \\
\hline 12 & 126.4514 & 128.3868 & 118.0643 & 114.1933 & 126.4514 & 128.3868 & 109.6772 \\
\hline 13 & 140.6449 & 128.3868 & 128.3868 & 123.2256 & 140.6449 & 143.8707 & 167.7416 \\
\hline 14 & 92.90304 & 92.90304 & 92.90304 & 100.645 & 92.90304 & 92.90304 & 92.90304 \\
\hline 15 & 136.1288 & 143.8707 & 149.6771 & 143.8707 & 140.6449 & 143.8707 & 123.2256 \\
\hline 16 & 58.90311 & 58.90311 & 58.90311 & 66.45148 & 58.90311 & 58.90311 & 58.90311 \\
\hline 17 & 114.1933 & 118.0643 & 123.2256 & 136.1288 & 114.1933 & 114.1933 & 128.3868 \\
\hline 18 & 45.67733 & 45.67733 & 45.67733 & 47.35474 & 45.67733 & 45.67733 & 49.35474 \\
\hline 19 & 39.74186 & 45.67733 & 39.74186 & 56.70956 & 39.74186 & 39.74186 & 47.35474 \\
\hline 20 & 75.48372 & 81.29016 & 81.29016 & 75.48372 & 75.48372 & 75.48372 & 100.645 \\
\hline 21 & 45.67733 & 45.67733 & 45.67733 & 53.2257 & 45.67733 & 45.67733 & 49.35474 \\
\hline 22 & 39.74186 & 39.74186 & 39.74186 & 41.87088 & 39.74186 & 39.74186 & 47.35474 \\
\hline 23 & 41.87088 & 45.67733 & 47.35474 & 53.2257 & 41.87088 & 39.74186 & 39.74186 \\
\hline 24 & 45.67733 & 45.67733 & 45.67733 & 45.67733 & 45.67733 & 45.67733 & 45.67733 \\
\hline 25 & 39.74186 & 39.74186 & 39.74186 & 56.70956 & 39.74186 & 39.74186 & 49.35474 \\
\hline 26 & 39.74186 & 41.87088 & 39.74186 & 66.45148 & 39.74186 & 41.87088 & 41.87088 \\
\hline 27 & 45.67733 & 47.35474 & 45.67733 & 47.35474 & 45.67733 & 45.67733 & 45.67733 \\
\hline
\end{tabular}




\begin{tabular}{|c|c|c|c|c|c|c|c|}
\hline \multirow[t]{2}{*}{ Element group } & \multicolumn{7}{|c|}{ Optimal cross sections using MDM operator } \\
\hline & $\mathrm{DE}$ & PSO & GA & VPS & EVPS & $\mathrm{CBO}$ & HS \\
\hline 28 & 39.74186 & 39.74186 & 39.74186 & 53.2257 & 39.74186 & 39.74186 & 49.35474 \\
\hline 29 & 39.74186 & 39.74186 & 39.74186 & 74.1934 & 39.74186 & 39.74186 & 57.09666 \\
\hline 30 & 45.67733 & 45.67733 & 45.67733 & 49.35474 & 45.67733 & 45.67733 & 53.2257 \\
\hline 31 & 39.74186 & 47.35474 & 39.74186 & 58.90311 & 39.74186 & 39.74186 & 41.87088 \\
\hline 32 & 45.67733 & 47.35474 & 45.67733 & 62.64504 & 45.67733 & 45.67733 & 45.67733 \\
\hline Best weight (m³) & 21.03382 & 21.20483 & 21.22301 & 22.57956 & 21.03264 & 21.20394 & 22.16075 \\
\hline Worst weight $\left(\mathbf{m}^{3}\right)$ & 21.44113 & 22.08113 & 21.36968 & 24.12907 & 21.19636 & 21.69758 & 22.88688 \\
\hline Mean weight $\left(\mathrm{m}^{3}\right)$ & 21.22183 & 21.55488 & 21.21097 & 23.2212 & 21.08794 & 21.48144 & 22.43518 \\
\hline $\begin{array}{l}\text { Mean weight of the first quar- } \\
\text { ter of the best answers }\left(\mathrm{m}^{3}\right)\end{array}$ & 21.07914 & 21.30911 & 21.1322 & 22.84546 & 21.03296 & 21.34984 & 22.21064 \\
\hline \multirow[t]{2}{*}{ Element group } & \multicolumn{7}{|c|}{ Optimal cross sections using MDM operator } \\
\hline & $\mathrm{DE}$ & PSO & GA & VPS & EVPS & $\mathrm{CBO}$ & HS \\
\hline 1 & 39.74186 & 39.74186 & 39.74186 & 39.74186 & 39.74186 & 39.74186 & 39.7419 \\
\hline 2 & 159.3545 & 159.3545 & 136.1288 & 128.3868 & 159.3545 & 136.1288 & 159.3545 \\
\hline 3 & 45.67733 & 45.67733 & 53.2257 & 58.90311 & 45.67733 & 53.2257 & 45.6773 \\
\hline 4 & 109.6772 & 109.6772 & 115.4836 & 115.4836 & 109.6772 & 114.1933 & 118.0643 \\
\hline 5 & 45.67733 & 45.67733 & 45.67733 & 45.67733 & 45.67733 & 45.67733 & 45.6773 \\
\hline 6 & 39.74186 & 39.74186 & 39.74186 & 39.74186 & 39.74186 & 39.74186 & 39.7419 \\
\hline 7 & 85.80628 & 85.80628 & 94.19336 & 90.96756 & 85.80628 & 90.96756 & 94.1934 \\
\hline 8 & 45.67733 & 45.67733 & 45.67733 & 47.35474 & 45.67733 & 45.67733 & 45.6773 \\
\hline 9 & 39.74186 & 39.74186 & 39.74186 & 39.74186 & 39.74186 & 39.74186 & 39.7419 \\
\hline 10 & 85.80628 & 81.29016 & 90.96756 & 84.51596 & 85.80628 & 84.51596 & 90.9676 \\
\hline 11 & 45.67733 & 45.67733 & 45.67733 & 45.67733 & 45.67733 & 45.67733 & 45.6773 \\
\hline 12 & 126.4514 & 126.4514 & 118.0643 & 128.3868 & 126.4514 & 128.3868 & 128.3868 \\
\hline 13 & 140.6449 & 140.6449 & 136.1288 & 140.6449 & 140.6449 & 140.6449 & 128.3868 \\
\hline 14 & 92.90304 & 92.90304 & 92.90304 & 92.90304 & 92.90304 & 92.90304 & 75.4837 \\
\hline 15 & 140.6449 & 140.6449 & 146.4513 & 143.8707 & 140.6449 & 143.8707 & 118.0643 \\
\hline 16 & 58.90311 & 58.90311 & 58.90311 & 58.90311 & 58.90311 & 58.90311 & 100.645 \\
\hline 17 & 114.1933 & 114.1933 & 118.0643 & 115.4836 & 114.1933 & 115.4836 & 123.2256 \\
\hline 18 & 45.67733 & 45.67733 & 45.67733 & 45.67733 & 45.67733 & 45.67733 & 45.6773 \\
\hline 19 & 39.74186 & 39.74186 & 39.74186 & 39.74186 & 39.74186 & 39.74186 & 39.7419 \\
\hline 20 & 75.48372 & 75.48372 & 81.29016 & 81.29016 & 75.48372 & 75.48372 & 84.516 \\
\hline 21 & 45.67733 & 45.67733 & 45.67733 & 45.67733 & 45.67733 & 45.67733 & 45.6773 \\
\hline 22 & 39.74186 & 39.74186 & 39.74186 & 39.74186 & 39.74186 & 39.74186 & 39.7419 \\
\hline 23 & 41.87088 & 45.67733 & 47.35474 & 45.67733 & 41.87088 & 45.67733 & 45.6773 \\
\hline 24 & 45.67733 & 45.67733 & 45.67733 & 47.35474 & 45.67733 & 45.67733 & 45.6773 \\
\hline 25 & 39.74186 & 39.74186 & 39.74186 & 39.74186 & 39.74186 & 39.74186 & 39.7419 \\
\hline 26 & 39.74186 & 39.74186 & 39.74186 & 39.74186 & 39.74186 & 39.74186 & 39.7419 \\
\hline 27 & 45.67733 & 45.67733 & 45.67733 & 45.67733 & 45.67733 & 45.67733 & 45.6773 \\
\hline 28 & 39.74186 & 39.74186 & 39.74186 & 39.74186 & 39.74186 & 39.74186 & 39.7419 \\
\hline 29 & 39.74186 & 39.74186 & 39.74186 & 39.74186 & 39.74186 & 39.74186 & 39.7419 \\
\hline 30 & 45.67733 & 45.67733 & 45.67733 & 45.67733 & 45.67733 & 45.67733 & 45.6773 \\
\hline 31 & 39.74186 & 39.74186 & 39.74186 & 39.74186 & 39.74186 & 39.74186 & 39.7419 \\
\hline 32 & 45.67733 & 45.67733 & 45.67733 & 45.67733 & 45.67733 & 45.67733 & 45.6773 \\
\hline Best weight $\left(\mathbf{m}^{3}\right)$ & 21.03264 & 21.03289 & 21.204 & 21.4155 & 21.03264 & 21.19361 & 21.599 \\
\hline Worst weight $\left(\mathbf{m}^{3}\right)$ & 26.87214 & 21.34015 & 21.97769 & 23.53377 & 21.19361 & 21.38257 & 23.58114 \\
\hline Mean weight $\left(\mathrm{m}^{3}\right)$ & 21.38674 & 21.17073 & 21.25325 & 21.6641 & 21.05411 & 21.21835 & 21.7845 \\
\hline $\begin{array}{l}\text { Mean weight of the first quar- } \\
\text { ter of the best answers }\left(\mathrm{m}^{3}\right)\end{array}$ & 21.03452 & 21.06625 & 21.0653 & 21.5781 & 21.03264 & 21.19418 & 21.6417 \\
\hline
\end{tabular}


Table 3 Results of seven algorithms with and without the effect of the MDM operator a for the 72-bar spatial truss

\begin{tabular}{|c|c|c|c|c|c|c|c|}
\hline \multirow[t]{2}{*}{ Element group } & \multicolumn{7}{|c|}{ Optimal design cross sections $\left(\mathrm{cm}^{2}\right)$} \\
\hline & $\mathrm{DE}$ & PSO & GA & VPS & EVPS & $\mathrm{CBO}$ & HS \\
\hline 1 & 3.48171 & 3.66118 & 4.74713 & 3.30382 & 3.50739 & 3.52946 & 4.05312 \\
\hline 2 & 7.98971 & 7.96971 & 7.52118 & 7.61671 & 8.02602 & 7.96004 & 7.96456 \\
\hline 3 & 0.645 & 0.645142 & 0.645 & 0.765293 & 0.645 & 0.645 & 0.645 \\
\hline 4 & 0.645 & 0.647933 & 0.645 & 0.735822 & 0.645 & 0.645 & 0.645 \\
\hline 5 & 7.80517 & 8.01323 & 9.64392 & 7.41648 & 8.02012 & 8.23747 & 8.52025 \\
\hline 6 & 7.88914 & 8.05452 & 8.32191 & 8.1082 & 7.91804 & 7.96806 & 7.98543 \\
\hline 7 & 0.645 & 0.645012 & 0.645 & 0.657749 & 0.645 & 0.645 & 0.645 \\
\hline 8 & 0.645 & 0.645 & 0.645 & 0.688567 & 0.645 & 0.645 & 0.645 \\
\hline 9 & 12.95618 & 13.28061 & 10.64944 & 13.07056 & 12.93505 & 12.90876 & 11.4775 \\
\hline 10 & 8.066 & 8.06162 & 7.97908 & 8.30767 & 8.08651 & 7.98602 & 8.42243 \\
\hline 11 & 0.645 & 0.645804 & 0.645 & 0.689852 & 0.645 & 0.645 & 0.645 \\
\hline 12 & 0.645 & 0.647075 & 0.645 & 0.669355 & 0.645 & 0.645 & 0.645 \\
\hline 13 & 17.24166 & 16.56303 & 17.42695 & 17.76954 & 17.01553 & 16.809 & 17.66908 \\
\hline 14 & 8.09083 & 7.94918 & 8.2568 & 8.03206 & 8.00434 & 8.12052 & 7.69537 \\
\hline 15 & 0.645 & 0.645 & 0.645 & 0.697603 & 0.645 & 0.645 & 0.645 \\
\hline 16 & 0.645 & 0.645884 & 0.645 & 0.709157 & 0.645 & 0.645 & 0.645 \\
\hline Best weight (kg) & 326.8461 & 326.918 & 328.8411 & 328.5089 & 326.836 & 326.8382 & 327.4943 \\
\hline Worst weight (kg) & 327.2173 & 327.7539 & 343.1666 & 332.8895 & 327.1547 & 327.2083 & 331.1311 \\
\hline Mean weight (kg) & 326.9467 & 327.1117 & 332.8074 & 330.1385 & 326.9469 & 326.9932 & 328.9874 \\
\hline $\begin{array}{l}\text { Mean weight of the first quarter } \\
\text { of the best answers }(\mathrm{kg})\end{array}$ & 326.8668 & 326.8995 & 329.629 & 328.8586 & 326.8399 & 326.8838 & 328.1162 \\
\hline \multirow[t]{2}{*}{ Element group } & \multicolumn{7}{|c|}{ Optimal design cross sections (cm2) using MDM operator } \\
\hline & $\mathrm{DE}$ & PSO & GA & VPS & EVPS & $\mathrm{CBO}$ & HS \\
\hline 1 & 3.36539 & 3.46408 & 3.52378 & 3.96725 & 3.51423 & 3.47224 & 3.39257 \\
\hline 2 & 7.9879 & 7.98384 & 7.5751 & 8.02878 & 8.0201 & 7.91655 & 7.56433 \\
\hline 3 & 0.645 & 0.645 & 0.645 & 0.645 & 0.645 & 0.645 & 0.64517 \\
\hline 4 & 0.645 & 0.645 & 0.645 & 0.645729 & 0.645 & 0.645 & 0.645007 \\
\hline 5 & 8.03408 & 7.96783 & 8.26757 & 7.44775 & 8.23507 & 7.85295 & 7.92135 \\
\hline 6 & 7.97055 & 8.00214 & 7.9479 & 8.08984 & 7.92286 & 7.96018 & 8.40782 \\
\hline 7 & 0.645 & 0.645004 & 0.645 & 0.645 & 0.645 & 0.645 & 0.645 \\
\hline 8 & 0.645 & 0.645 & 0.645 & 0.645 & 0.645 & 0.645 & 0.645011 \\
\hline 9 & 12.70564 & 12.94365 & 11.99745 & 14.92544 & 12.68772 & 12.84103 & 12.69244 \\
\hline 10 & 8.03294 & 8.1152 & 8.38802 & 7.91379 & 8.02236 & 8.10305 & 8.15031 \\
\hline 11 & 0.645 & 0.645001 & 0.645 & 0.645326 & 0.645 & 0.645002 & 0.645051 \\
\hline 12 & 0.645 & 0.645 & 0.645 & 0.645 & 0.645 & 0.645 & 0.645038 \\
\hline 13 & 17.3718 & 17.10232 & 17.75176 & 15.6739 & 17.04146 & 17.31419 & 17.47851 \\
\hline 14 & 8.04145 & 7.93454 & 8.16132 & 8.00375 & 8.06917 & 8.05503 & 7.95521 \\
\hline 15 & 0.645 & 0.645 & 0.645 & 0.645754 & 0.645 & 0.645 & 0.645068 \\
\hline 16 & 0.645 & 0.645 & 0.645 & 0.645 & 0.645 & 0.645 & 0.645 \\
\hline Best weight (kg) & 326.8426 & 326.8351 & 327.2173 & 327.7539 & 326.831 & 326.8322 & 327.1657 \\
\hline Worst weight (kg) & 327.1956 & 327.4619 & 339.7943 & 331.8207 & 327.012 & 327.1118 & 330.124 \\
\hline Mean weight (kg) & 326.909 & 327.094 & 331.9036 & 329.4437 & 326.865 & 326.9341 & 328.889 \\
\hline $\begin{array}{l}\text { Mean weight of the first quarter } \\
\text { of the best answers }(\mathrm{kg})\end{array}$ & 326.8505 & 326.8551 & 329.103 & 328.3882 & 326.8367 & 326.8617 & 327.959 \\
\hline
\end{tabular}




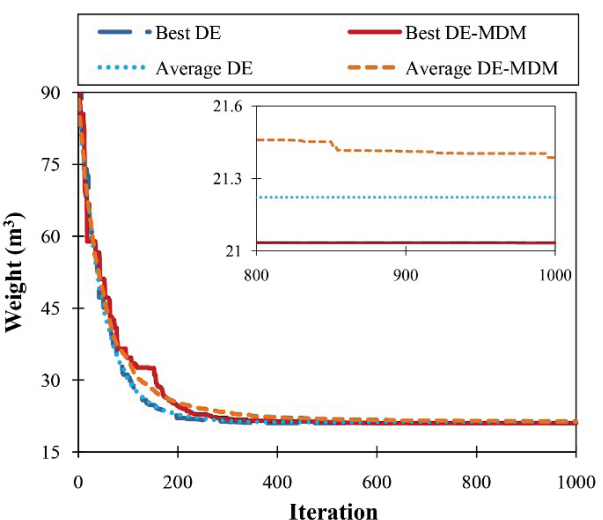

(a)

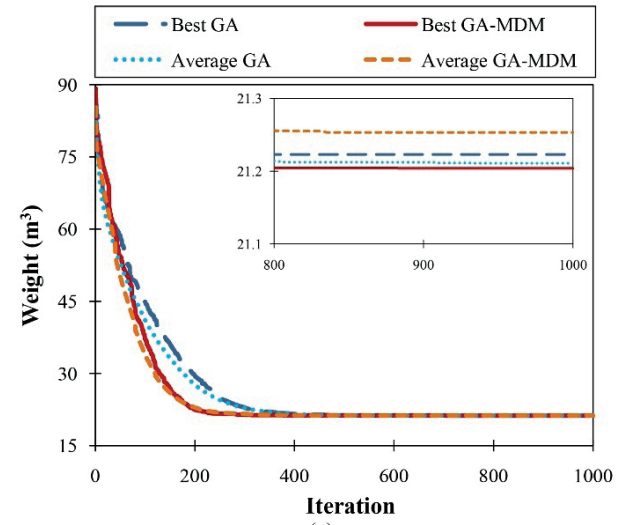

(c)

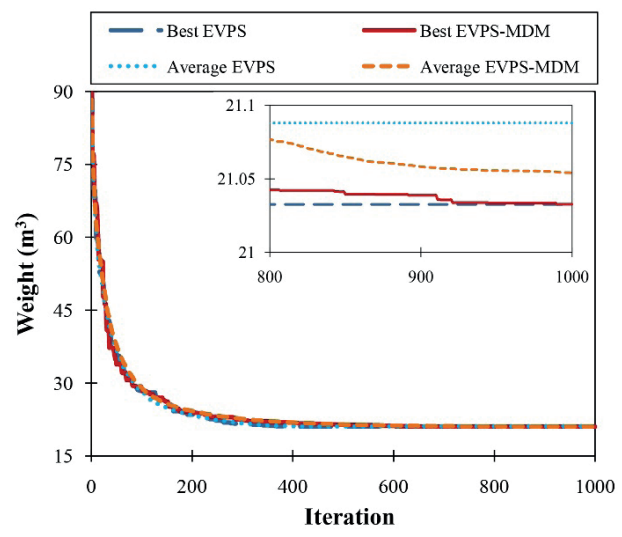

(e)

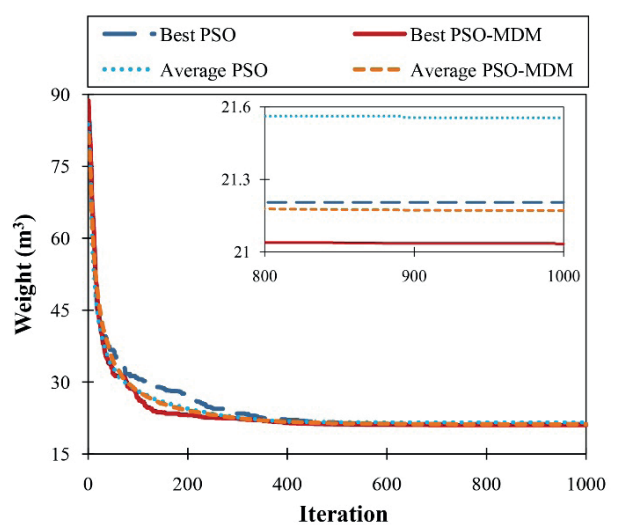

(b)

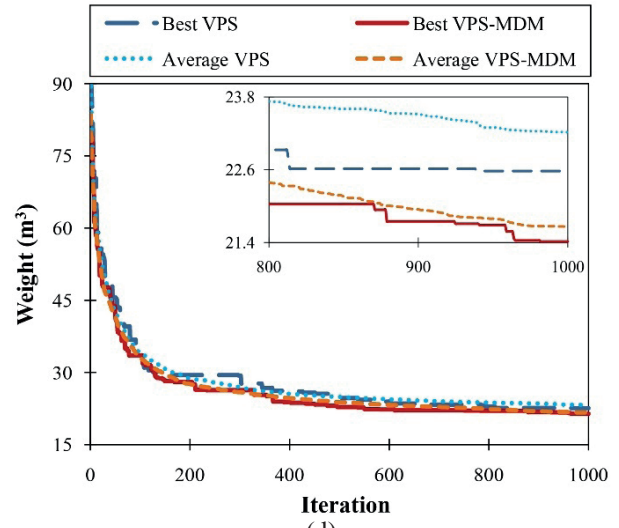

(d)

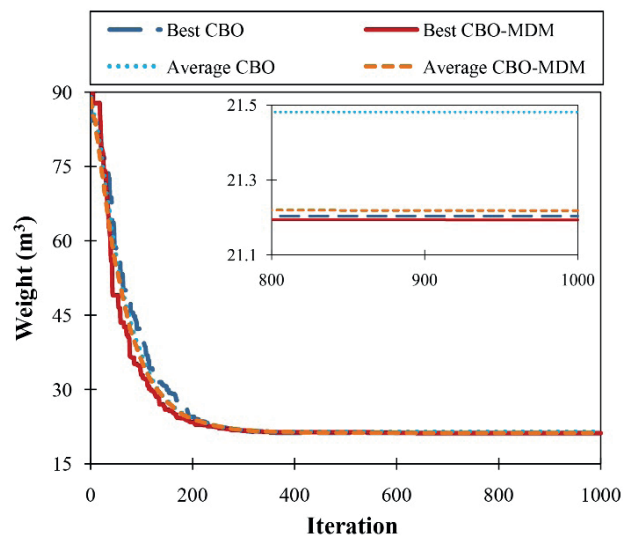

(f)

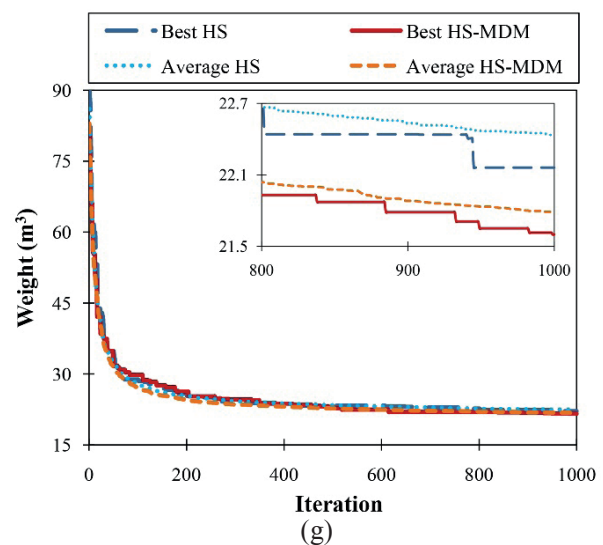

Fig. 4 Convergence curves of the seven algorithms with and without the effect of the MDM operator for the best optimal design and average answer for the 582-bar tower truss 


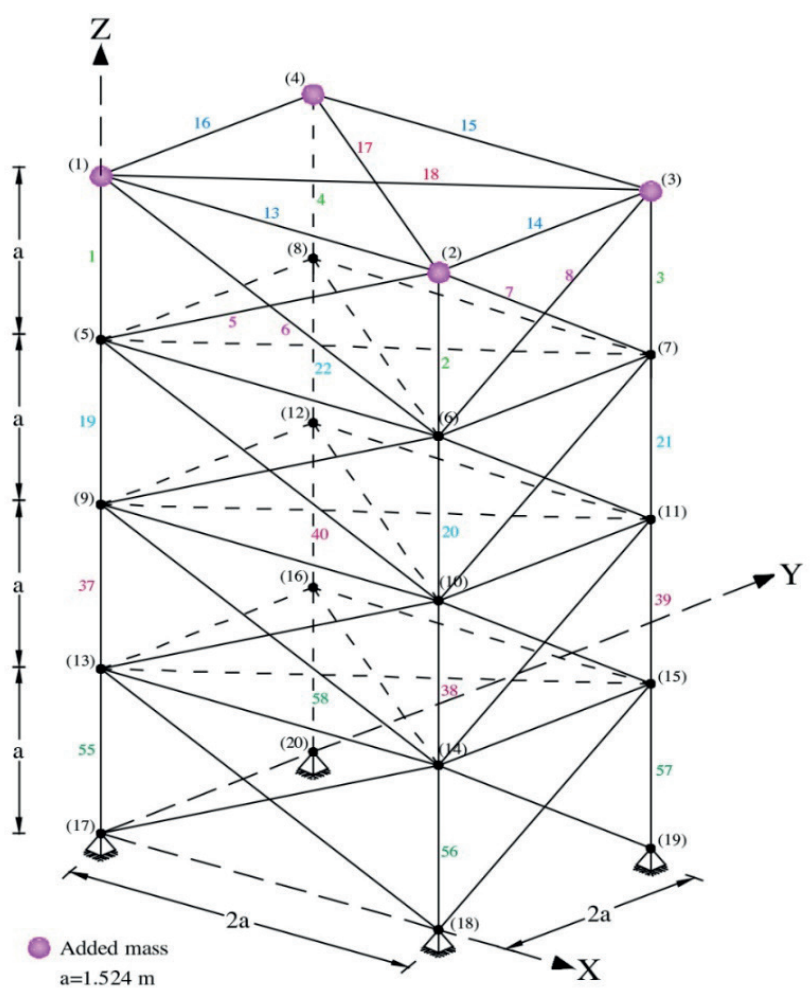

Fig. 5 Schematic of the 72-bar spatial truss.

\section{Discussion}

As mentioned in section 4, the number of independent runs, population size and the number of iterations are assumed to be large enough, so that we can expect suitable values for all algorithms and problems. However according to the tables and figures the following results can be obtained:

The optimum designs for all the problems are improved using the effect of the MDM operator. Also, mean weight and mean weight of the first quarter of the best answers are enhanced.

The quantity of the effect of the MDM operator is different for each problem and algorithms. The quality of the optimum design of each algorithm is one of the most important factors.

The best optimum result of all algorithm with the effect of this operator is almost near to the best-achieved answer. In other words, the difference between all optimum results with the effect of the MDM operator, have not great values. In Figs. 7, 8 and 9, the weight difference of each best, mean and mean of the first the first quarter of the best answers relative to the case without the effect of MDM operator are presented for all 3 problems and all utilized algorithms. Figure 10 is similar to Figs. 7, 8 and 9, with a different that in this figure the population size and iteration number are considered as 30 and 500, respectively.
It can be observed that when the population size and iteration number have lower values, the effect of the MDM operator becomes more tangible.

These figures show the efficiency of the MDM operator for the best, mean and mean weight of the first quarter of the best answers for all the considered methods. These figures illustrate that all results are improved. Also, the results show that this operator improved the behavior of all the algorithms for all three problems. In another word, according to figures and tables, this operator causes to reach more reliable answers for all algorithms and problems.

All problems and algorithms were performed in 30 independent runs and the number of populations and iterations were taken 60 and 1000, respectively. Thus, with respect to these cases, each algorithm is expected to provide a very satisfactory answer. Therefore, the mean weight, mean weight of the first quarter of the best answers and the worst answers were presented for better comparison. Some of the results, with and without the MDM operator, were not significantly different, which can be attributed to the suitable performances of the algorithm for a specific problem and also the correct tuning of the algorithm's parameters. When an algorithm presents a suitable answer, it is clear that the performance of the MDM operator will not very tangible. When an algorithm does not present a suitable answer for a specific problem the effect of using the operator will more apparent. The operator's impact is quite obvious for the following problems:

- PSO, GA, VPS and CBO algorithms in the first problem.

- VPS and HS algorithms in the second problem.

- GA and VPS in the last problem.

\section{Conclusions}

In this study, the MDM operator is used to improve the behavior of seven algorithms consisting of DE, PSO, GA, VPS, EVPS, CBO and HS algorithms. The MDM operator does not cause any change in the main steps of the metaheuristic algorithms and controls the population dispersion and enhances the searchability of the algorithms and for the most of the problems, this operator improves the speed of convergence. The results show the efficiency of this operator for three optimization problems consisting of two trusses and one frame structures. All of the considered problems are well-known problems in structural optimization literature. Almost all of the results are for the best optimal design, mean weight and mean weight of the first quarter of the best answers are improved in comparison to the 


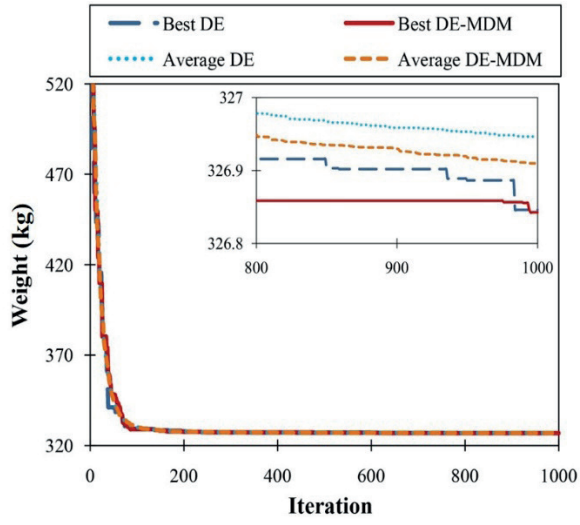

(a)

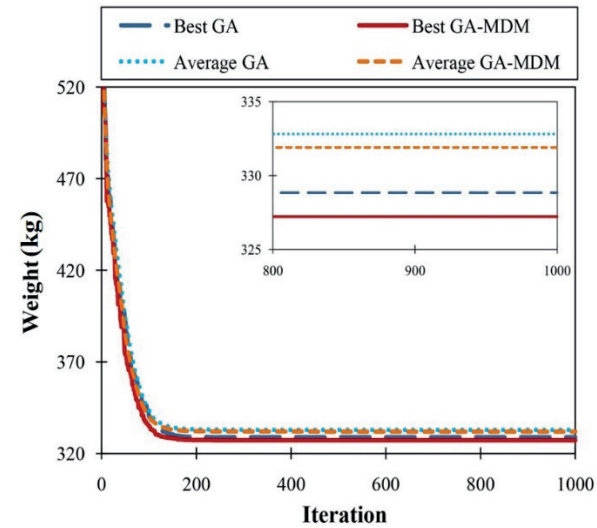

(c)

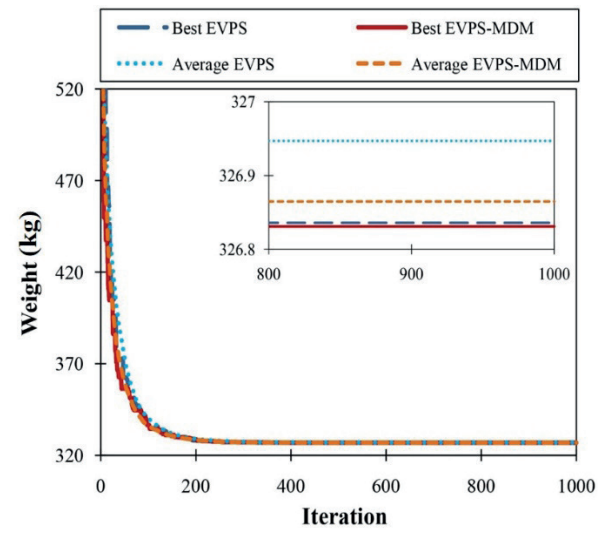

(e)

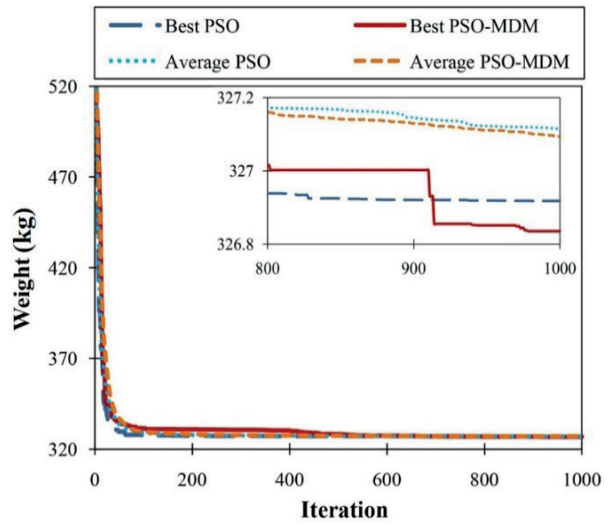

(b)

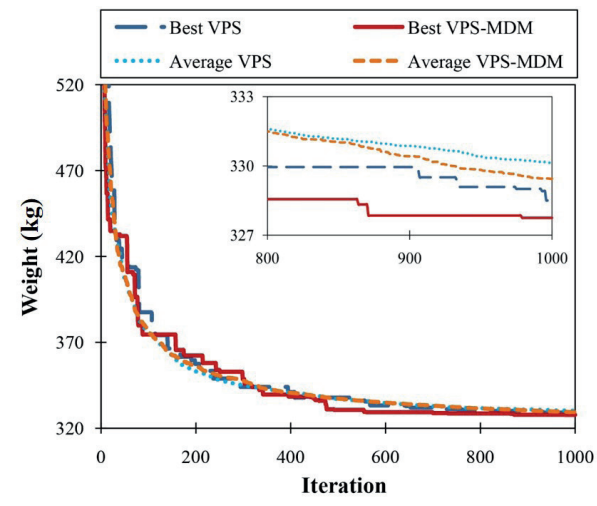

(d)

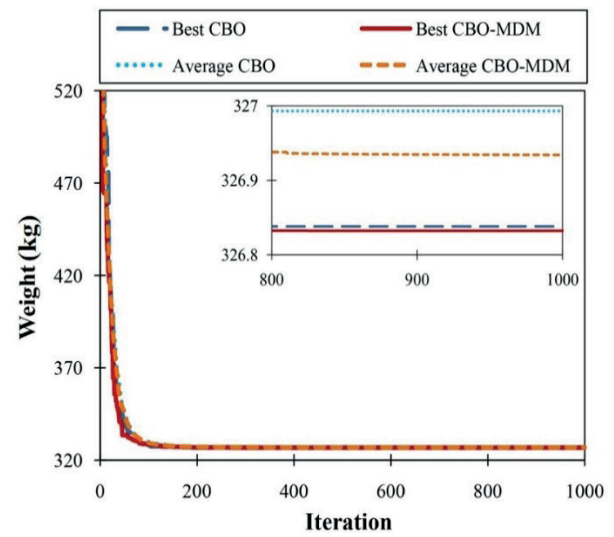

(f)

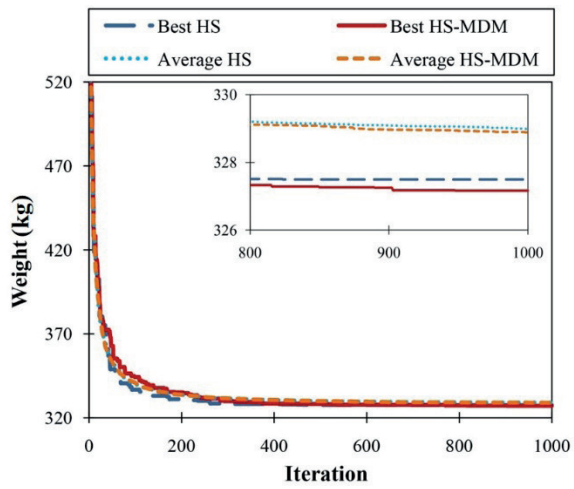

(g)

Fig. 6 Convergence curves of the seven algorithms with and without the effect of the MDM operator for the best optimal design and average answer for the 72-bar spatial truss 


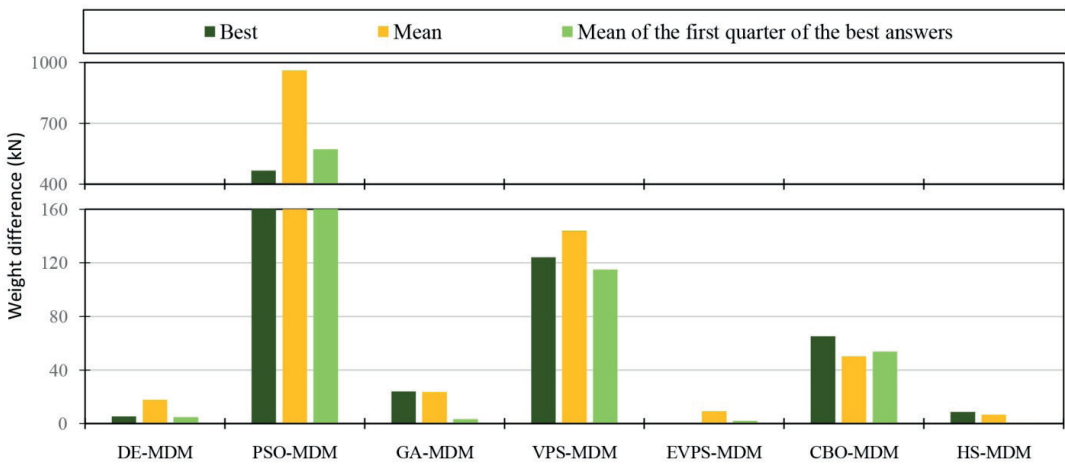

Fig. 7 Comparison of the results according to weight differences for the first problem.

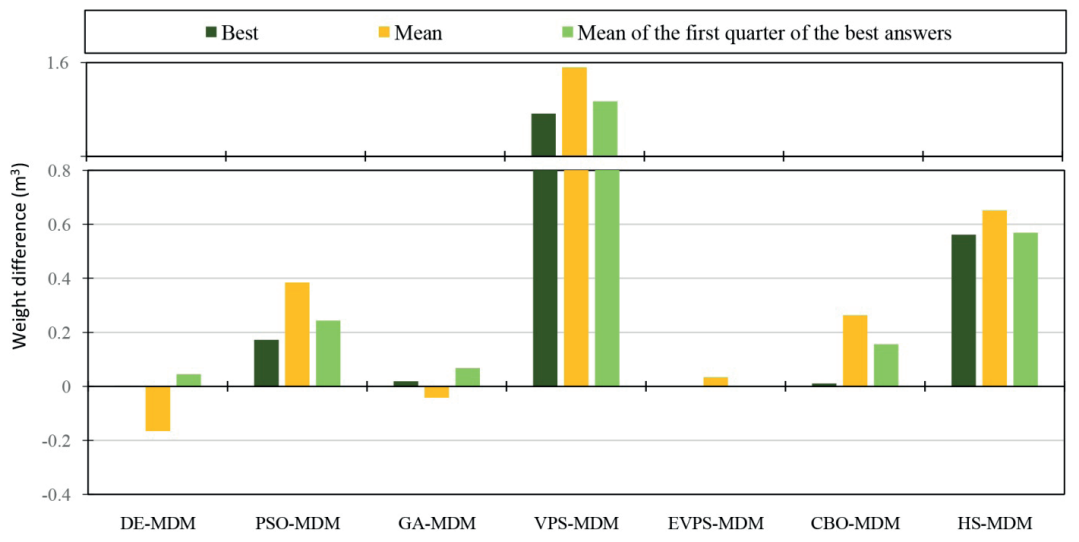

Fig. 8 Comparison of the results according to weight difference for second problem.

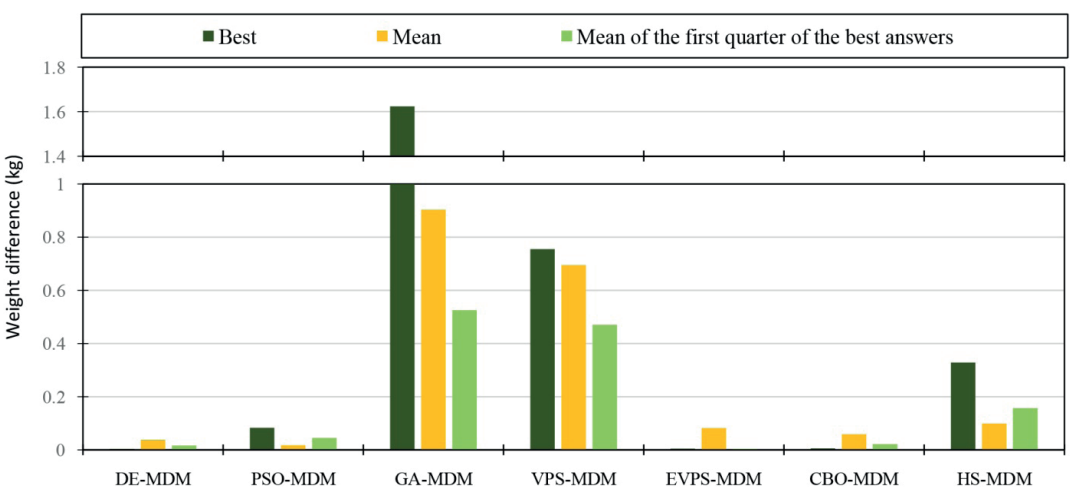

Fig. 9 Comparison of the results according to weight difference for last problem.

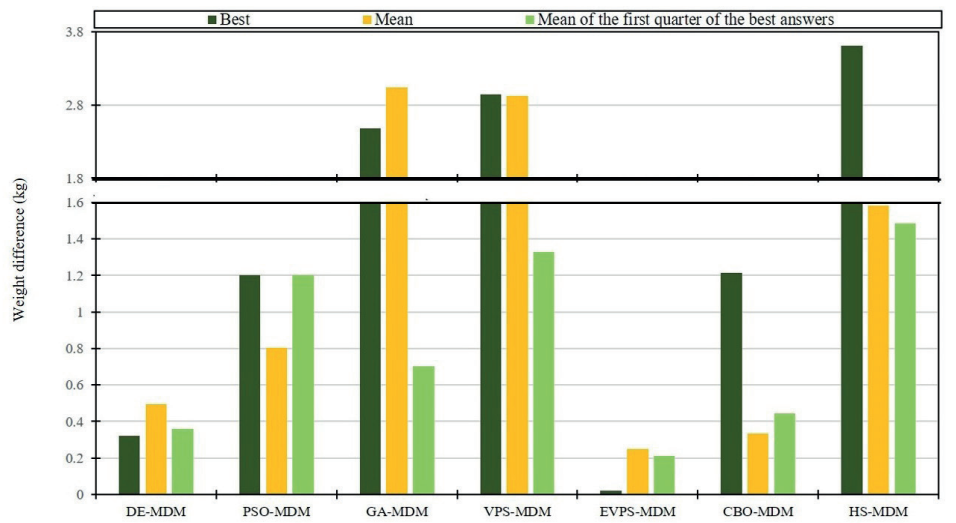

Fig. 10 Comparison of the results according to weight differences for 3rd example with lower population size and iteration. 
results of the algorithms without the effect of this operator. Another achievement of this operator, the results show that this operator reduces the dependency of the algorithms to their parameter tuning and the types of the problems. In each iteration, the population within the pre-defined range must be certain. This value (Eq. (1)) will ascend in each iteration, so with the increases in iterations, the population (for each variable) within this range will increase. Thus, the balance between exploration and exploitation will be established. In fact, this balance will be improved by controlling the population within the pre-defined range.

Finally, the authors recommend the use of this operator for other metaheuristic algorithms and for other types of optimization problems.

\section{References}

[1] Gandomi, A. H., Yang, X-S. Talatahari, S., Alavi, A. H. eds., "Metaheuristic applications in structures and infrastructures", 1st ed., Elseiver, London, Great-Britain, 2013.

[2] Holland, J. H. "Adaptation in natural and artificial systems: an introductory analysis with applications to biology, control, and artificial intelligence", 1st ed., University of Michigan Press, Ann Arbor, United States, 1975.

[3] Storn, R., Price, K. "Differential evolution-a simple and efficient heuristic for global optimization over continuous spaces", Journal of Global Optimization, 11(4), pp. 341-359, 1997. https://doi.org/10.1023/A\%3A1008202821328

[4] Eberhart, R., Kennedy, J. "A new optimizer using particles warm theory", In: Proceedings of the Sixth International Symposium on Micro Machine and Human Science, Nagoya, Japan, 1995. pp. 39-45. https://doi.org/10.1109/MHS.1995.494215

[5] Jayabarathi, T., Raghunathan, T., Gandomi, A. "The bat algorithm, variants and some practical engineering applications: a review", In: Yang, X.-S. ed., Nature-Inspired Algorithms and Applied Optimization, 1st ed., Springer, New York, United States, 2018, pp. 313-330.

https://doi.org/10.1007/978-3-319-67669-2

[6] Kaveh, A., Farhoudi, N. "A new optimization method: Dolphin echolocation", Advances in Engineering Software, 59, pp. 53-70, 2013. https://doi.org/10.1016/j.advengsoft.2013.03.004

[7] Kaveh, A., Hosseini, P. "A simplified dolphin echolocation optimization method for optimum design of trusses", International Journal of Optimization in Civil Engineering, 4(3), pp. 381-397, 2014. [online] Available at: http://ijoce.iust.ac.ir/article-1-183-en.pdf [Accessed: 31.01.2019]

[8] Kaveh, A., Hosseini Vaez, S. R., Hosseini, P. "Simplified dolphin echolocation algorithm for optimum design of frame", Smart Structures and Systems, 21(3), pp. 321-333, 2018. https://doi.org/10.12989/sss.2018.21.3.321

[9] Mirjalili, S., Mirjalili, S. M., Lewis, A. "Grey Wolf Optimizer", Advances in Engineering Software, 69, pp. 46-61, 2014. https://doi.org/10.1016/j.advengsoft.2013.12.007
[10] Kaveh, A. Hosseini Vaez, S. R., Hosseini, P. "Matlab Code for an Enhanced Vibrating Particles System Algorithm", International Journal of Optimization in Civil Engineering, 8(3), pp. 401-414, 2018. [online] Available at: http://ijoce.iust.ac.ir/article-1-352-en. pdf [Accessed 31.01.2019]

[11] Kaveh, A., Hosseini Vaez, S. R., Hosseini, P. "Enhanced vibrating particles system algorithm for damage identification of truss structures" International Journal of Science and Tecnology - Scientia Iranica, 2017, [online] https://doi.org/10.24200/SCI.2017.4265

[12] Sun, G., Zhang, H., Fang, J., Li, G., Li, Q. "A new multi-objective discrete robust optimization algorithm for engineering design", Applied Mathematical Modelling, 53, pp. 602-621, 2018. https://doi.org/10.1016/j.apm.2017.08.016

[13] Kaveh, A., Mahdavi, V. R. "Colliding bodies optimization: A novel metaheuristic method", Computers \& Structures, 139, pp. 18-27, 2014.

https://doi.org/10.1016/j.compstruc.2014.04.005

[14] Geem, Z. W., Kim, J. H., Loganathan, G. V. "A new heuristic optimization algorithm: harmony search", Simulation, 76(2), pp. 60-68, 2001.

https://doi.org/10.1177/003754970107600201

[15] Gandomi, A. H., Alavi, A. H. "Krill herd: a new bio-inspired optimization algorithm", Communications in Nonlinear Science and Numerical Simulation, 17 (12), pp. 4831-4845, 2012. https://doi.org/10.1016/j.cnsns.2012.05.010

[16] Tabari, A., Ahmad, A. "A new optimization method: Electro-Search algorithm", Computers \& Chemical Engineering, 103, pp. 1-11, 2017. https://doi.org/10.1016/j.compchemeng.2017.01.046

[17] Zhang, W., Li, D., Yuan, J., Song, J., Guo, X. "A new three-dimensional topology optimization method based on moving morphable components (MMCs)", Computational Mechanics, 59(4), pp. 647665,2017 https://doi.org/10.1007/s00466-016-1365-0

[18] Venkata Rao, R. "Jaya: A simple and new optimization algorithm for solving constrained and unconstrained optimization problems", International Journal of Industrial Engineering Computations, 7, pp. 19-34, 2016.

https://doi.org/10.5267/j.ijiec.2015.8.004

[19] Mirjalili, S., Gandomi, A. H., Mirjalili, S. Z., Saremi, S., Faris, H., Mirjalili, S. M. "Salp swarm algorithm: a bio-inspired optimizer for engineering design problems", Advances in Engineering Software, 114, pp. 163-191, 2017. https://doi.org/10.1016/j.advengsoft.2017.07.002

[20] Du, T-S., Ke, X-T., Liao, J-G., Shen, Y-J. "DSLC-FOA: Improved fruit fly optimization algorithm for application to structural engineering design optimization problems", Applied Mathematical Modelling, 55, pp. 314-339, 2018. https://doi.org/10.1016/j.apm.2017.08.013

[21] Prayogo, D., Cheng, M-Y., Wu, Y-W., Herdany, A. A., Prayogo, H. "Differential Big Bang-Big Crunch algorithm for construction-engineering design optimization", Automation in Construction, 85, pp. 290-304, 2018. https://doi.org/10.1016/j.autcon.2017.10.019 
[22] Kaveh, A. "Advances in Metaheuristic Algorithms for Optimal Design of Structures", 2nd ed., Springer, Basel, Switzerland, 2017. https://doi.org/10.1007/978-3-319-05549-7

[23] Galambos, T. V. "Load and Resistance Factor Design (LRFD)", Engineering Journal, American Institute of Steel Construction, 18, pp. 74-82, 1981. [online] Available at: https://www.aisc.org/ globalassets/aisc/awards/tr-higgins/past-winners/load-and-resistance-factor-design.pdf [Accessed 31.01.2019]

[24] Kaveh, A., Ilchi Ghazaan, M. "Vibrating particles system algorithm for truss optimization with multiple natural frequency constraints", Acta Mechanica, 228(1), pp. 307-322, 2017. https://doi.org/10.1007/s00707-016-1725-z
[25] Kaveh, A., Farhoudi, N. "Dolphin monitoring for enhancing metaheuristic algorithms: Layout optimization of braced frames", Computers \& Structures, 165, pp. 1-9, 2016. https://doi.org/10.1016/j.compstruc.2015.11.012

[26] Kaveh, A., Hosseini Vaez, S. R., Hosseini, P. "Modified dolphin monitoring operator for weight optimization of frame structures", Periodica Polytechnica Civil Engineering, 61(4), pp. 770-779, 2017. https://doi.org/10.3311/PPci.9691

[27] Kaveh, A., Hosseini Vaez, S. R., Hosseini, P., Ezzati, E. "Layout optimization of planar braced frames using modified dolphin monitoring operator", Periodica Polytechnica Civil Engineering, 62(3), pp. 717-731, 2018.

https://doi.org/10.3311/PPci.11654 